\title{
Perancangan dan Pengembangan Avatar Character 2D Menggunakan Metode PDDIE
}

\author{
Tony Wibowo ${ }^{1}$, Felicia Canesta ${ }^{2}$ \\ ${ }^{1,2}$ Sistem Informasi, Fakultas Ilmu Komputer, Universitas Internasional Batam

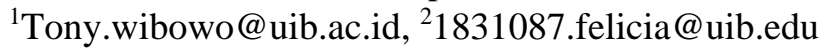

\begin{abstract}
Abstrak
Seiring dalam berjalannya waktu, bentuk karya seni dalam teknologi komputer mencapai cara yang populer di dalam aspek kehidupan. Salah satu bentuknya berupa "Digital Art". Digital art merupakan sebuah karya seni yang dilakukan dengan menggunakan teknologi digital ataupun dengan teknologi komputer yang dapat berupa gambar, video, game, dan lain-lain. Tujuan penerapan digital art dalam perancangan ini adalah untuk menjadikan proses pembelajaran menjadi hal yang menarik dan tidak membosankan bagi pelajar. Menciptakan aspek berbeda dalam pembelajaran yang menekankan studi ini untuk mengangkat topik berupa "Perancangan Digital Avatar untuk Pembelajaran Online Berbasis Gamifikasi”. Dalam tahap perancangan / desain avatar, penelitian ini menggunakan metode pengembangan PDDIE (Planning, Design, Development, Implementation, Evaluation). Metode perancangan ini digunakan dalam pengembangan seni digital berupa "avatar" yang menggunakan teknik Digital Illustration secara 2D dalam sistem pembelajaran online. Penerapan dan pengembangan tersebut yang akhirnya dapat membuat suasana pembelajaran menjadi lebih bermakna bagi pelajar ataupun pendidik dalan institusi Pendidikan.
\end{abstract}

Kata kunci: digital art, pembelajaran online, gamifikasi, avatar

\section{Design and Development of 2D Character Avatars Using the PDDIE Method}

\begin{abstract}
Over time, art forms in computer technology have attained a popular way in aspects of life. One of the forms is "Digital Art". Digital art is a work of art that is done using digital technology or computer technology, which can be in the form of images, videos, games, and others. The purpose of implementing digital art in this design is to make the learning process interesting and not boring for students. Creating a different aspect of learning that emphasizes this study to raise the topic of "Designing Digital Avatars for Gamification-Based Online Learning". In the avatar design / design stage, this study uses the PDDIE (Planning, Design, Development, Implementation, Evaluation) development method. This design method is used in the development of digital art in the form of "avatars" using the 2D Digital Illustration technique in the online learning system. This application and development can ultimately make the learning atmosphere more meaningful for students or educators in educational institutions.
\end{abstract}

Keywords: digital art, online learning, gamification, avatar 


\section{Pendahuluan}

Sejak awal tahun 1950, bentuk karya seni dalam teknologi komputer mencapai cara yang populer di dalam aspek kehidupan. Salah satu bentuknya berupa "Digital Art”(Zaini \& Analisis, 2017). Digital art merupakan sebuah karya seni yang dilakukan dengan menggunakan teknologi digital ataupun dengan teknologi komputer yang dapat berupa gambar, video, game, dan lain-lain (Tjiptawan et al., 2019). Siapapun bisa memanfaatkan digital art dalam mengembangkan usaha-nya di berbagai sektor. Tentunya salah satu sektor tersebut ialah dalam bidang Pendidikan. Penggunaan digital art dalam bidang pendidikan menjadi salah satu teknik yang diyakini dapat mengembangkan minat belajar pada pelajar (Verawati, 2020). Hal tersebut tentu membuat pendidikan dapat meraih keuntungan dengan menerapkan digital arts ke dalam proses pembelajarannya (Martin \& Bolliger, 2018).

Pentingnya penerapan digital art dalam pendidikan adalah untuk menjadikan proses pembelajaran menjadi hal yang menarik dan tidak membosankan bagi pelajar (Jusuf, 2016). Penerapan seni digital dilakukan karena mengingat besarnya tingkat kemalasan pada pelajar di seluruh dunia yaitu sebesar $66 \%$. Besar persen tersebut dilaporkan dari hasil penelitian oleh International Assessment of Educational Progress, yang menyatakan bahwa banyak pelajar mengalami kemalasan dan kesulitan dalam memahami materi yang diajarkan oleh pendidiknya (Doyle, 2020). Fenomena tersebut terjadi karena para pelajar tidak memiliki motivasi dalam belajar yang diajarkan secara tatap muka ataupun melalui online. Pelajar juga kesulitan dalam mengartikan materi yang diajarkan sebab telah merasa jenuh atas sistem belajar yang diterapkan (Antonaci et al., 2019). Pada hal ini, sistem yang diterapkan dapat berupa buku-buku materi, rangkaian tulisan dalam media pembelajarannya, dan juga ajaran pendidik yang kurang memuaskan. Hal itulah yang akhirnya menimbulkan kurangnya semangat belajar pada siswa yang mengalaminya (Doyle, 2020).

Pergumulan tersebut yang akhirnya menekankan studi ini untuk mengubah sistem pembelajaran tersebut menjadi sistem yang lebih modern dan juga menarik untuk dipelajari. Salah satu cara yang dapat mengubahnya yaitu dengan mengimplementasikan digital art secara khusus pada pembelajaran yang berbasis online-learning / blended learning. Penerapan ini diimplementasi khusus pada pembelajaran berbasis online karena dinilai cukup mudah saat diakses oleh siapapun, kapanpun dan dimanapun (Martin \& 
Bolliger, 2018). Sehingga keduanya menjadi cara yang pas untuk dapat dimanfaatkan sebagai media pembelajaran yang menerapkan seni digital (Wang, 2019). Berbagai rancangan pembelajaran berbasis elemen digital art juga telah populer sejak tahun (Baca et al., 2019). Salah satu contoh penerapan pembelajaran yang menggunakan elemen digital art adalah situs bernama "Kahoot!". Sejak tahun 2013, situs ini menjadi populer dan dijadikan sebagai salah satu platform pembelajaran berbasis permainan pada institusi Pendidikan. Aplikasi \& situs Kahoot dirancang dengan menggunakan teknik digital art berupa "Game Art" sehingga menjadikannya tampak atraktif. Pembelajarannya berupa kuis pilihan ganda yang materinya dapat diisi / ditentukan sendiri oleh sang pendidik. Kahoot juga menyediakan fitur timer yang membuat para pengguna menjadi lebih kompetitif dan aktif berpartisipasi. Itulah yang akhirnya mendorong para digital-artist untuk mengembangkan ide model pembelajaran dalam aspek yang berbeda, seperti melalui digital art atau animation-art (Basuki \& Hidayati, 2019).

Beberapa cakupan masalah didapati dari latar belakang di atas yaitu bagaimana cara penulis dapat mengembangkan digital avatar sebagai elemen pendukung pada sistem Pendidikan dan bagaimana cara penulis mengembangkan digital avatar dengan metode 2D menggunakan teknik digital illustration. Terdapat juga tujuan dari perancangan dan penerapan Digital Avatar pada pembelajaran yaitu untuk sebagai alat pemicu kesenangan dalam diri setiap pelajar. Dengan penerapan tersebut yang akhirnya dapat membuat suasana pembelajaran menjadi lebih bermakna bagi pelajar ataupun pendidik. Menciptakan aspek berbeda dalam pembelajaran yang akhirnya menekankan studi penerapan ini untuk mengangkat topik berupa "Perancangan Digital Avatar untuk Pembelajaran Online Berbasis Gamifikasi”. Upaya tersebut diterapkan sebagai cara untuk pelajar dapat menciptakan pengetahuan mereka sendiri, yang akhirnya mengarah ke tingginya tingkat kesuksesan di dunia pendidikan melalui digital art.

Perancangan ini didasarkan pada penelitian-penelitian yang telah berkontribusi dalam mengembangkan bidang perancancangan digital art. Penelitian yang menjadi dasar utama pada studi perancangan ini adalah penelitian yang dilakukan oleh Tianean et al (2020) yaitu membahas tentang perancangan dasar yang atraktif dari sebuah desain karakter yang dilakukan melalui teknik Digital Illustration. Penulis merencanakan terlebih dahulu apa objek yang akan digambar nantinya dan kemudian diilustrasikan, Penelitian tersebut akhirnya membuktikan bahwa hasil yang didapati dari sekelompok 
masyarakat tentang perancangan tersebut dapat memberikan tingkat kepuasan, motivasi dan kesenangan dalam diri mereka ketika menggunakannya. Selain itu penelitian S. Zhou \& Guo (2018) juga menekankan bahwa perancangan ilustrasi digital adalah untuk memotivasi \& mengembangkan citra seni khususnya pada sistem Pendidikan. Maka itu pengembangan yang dilakukan oleh penelitian tersebut tidak hanya sebatas mengenalkan kepada masyarakat, tetapi juga membuka peluang bagi siapapun yang tertarik untuk "menciptakan" karakter ilustrasi digital itu sendiri. Penelitian tersebut juga mendukung hasil penelitian Richards et al (2017) \& Janottama \& Putraka (2017) yang membuktikan penerapan ilustrasi karakter digital dalam pembelajaran yang berbasis gamifikasi menimbulkan nilai-nilai motivasi yang didapatkan dari perancangan ilustrasi digital pada sistem pembelajaran berbasis gamifikasi tersebut. Penelitian pendukung yang terakhir pada topik ini dilakukan oleh Arifin \& Wijaya (2018) yang membuktikan bahwa perancangan elemen-elemen ilustrasi digital dapat memberi suasana baru dalam pembelajaran berbasis online. Penelitian tersebut menunjukkan bahwa sebagai peserta didik dapat berperan aktif dan maksimal apabila difasilitasi dengan optimal sehingga dapat belajar secara maksimal.

Dalam tahap perancangan / desain avatar, penelitian ini menggunakan metode pengembangan PDDIE (Planning, Design, Development, Implementation, Evaluation). Metode PDDIE dilakukan berdasarkan penelitian terapan yang pernah dilakukan oleh Tianean et al (2020) dalam merancang digital character $2 D$ pada penelitiannya. Visual karakter avatar adalah bagian yang sangat penting dari proses ilustrasi. Berikut merupakan model pengembangan pada perancangan digital avatar:

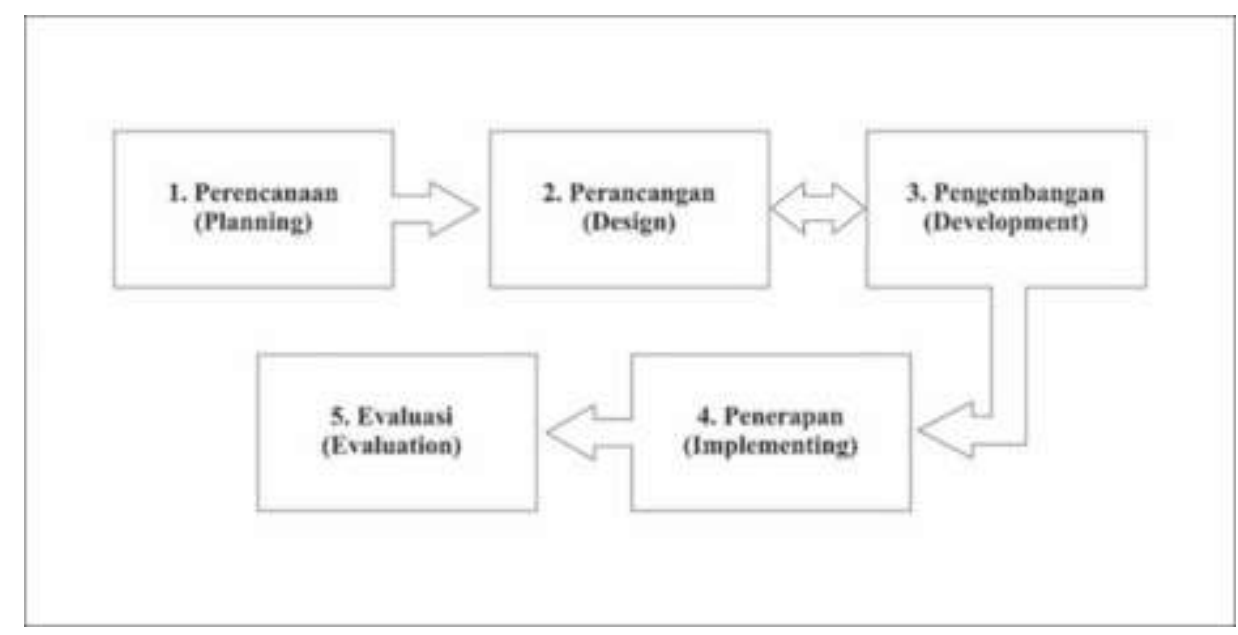

Gambar 1. Metode Awal Pengembangan hingga Finalisasi 
Pada Gambar 1, metode awal pengembangan digital avatar hingga pada proses finalisasi dijabarkan dengan tahap sebagai berikut, yakni: 1) Tahap Perencanaan (Planning) yaitu perencanaan awal ilustrasi untuk mendapatkan gambaran seperti apa kira-kira karakter yang akan dibuat. Perencanaan ini dapat dilakukan dengan melakukan gambaran kasar (sketching) dan menentukan perpaduan warna yang cocok pada tiap gender avatar, 2) Tahap Perancangan Avatar (Avatar Design) yaitu tahap perancangan digital avatar character $2 D$ yang akan dikembangkan. Kegiatan tersebut dilakukan dengan melakukan pemilihan sebuah media pembelajaran yang mendukung (Website), perancangan tahap awal produk (Digital Avatar), dan melakukan penyusunan instrumen penelitian. Kemudian hasil dari rancangan digital avatar tersebutlah yang kemudian dijadikan sebagai prototype dan kemudian akan divalidasi, 3) Tahap Pengembangan Avatar (Development) yaitu tahapan validasi dari prototype 1. Kemudian hasil validasi akan dijadikan sebagai masukan / feedback untuk memperbaiki hasil revisi dari perancangan tersebut. Hasil revisi tersebut yang kemudian akan digunakan untuk prototype selanjutnya, 4) Tahap Implementasi Avatar (Implementation) yaitu tahapan dimana penulis melakukan uji coba terhadap hasil final dari media yang akan dikembangkan. Tujuannya adalah untuk mendapatkan review atau feedback yang lebih baik untuk dapat meningkatkan kualitas hasil paling akhir dari perancangan tersebut, dan 5) Tahap Evaluasi Avatar (Evaluation) yaitu tahapan dimana penulis melakukan uji coba terhadap hasil final dari media yang akan dikembangkan. Dalam hal ini, uji coba dilakukan sementara hanya kepada dosen. Setelah perancangan tersebut di review oleh dosen pembimbing, akan dilakukan proses akhir dalam pengembangan model PDDIE yakni tahap evaluasi. Hal ini penting untuk dilakukan agar penulis dapat mengetahui, cukup layak-kah perancangan ini diimplementasikan.

Terdapat juga alur perancangan dalam pembuatan karakter digital art avatar $2 D$ yaitu dengan menggunakan kerangka kerja Sketching, Illustrating, Coloring, dan Exporting. Proses sketching dilakukan dengan penggambaran secara kasar agar mendapatkan gesture dari avatar tersebut, kemudian proses illustrating dilakukan untuk menghasilkan sebuah gambaran ilustrasi agar dapat diberi warna, proses coloring dilakukan untuk memberi warna pada tiap elemen avatar yang dibuat, dan proses exporting adalah dimana penulis melakukan export hasil final digital avatar yang telah 
dirancang. Kerangka kerja tersebut tentu dapat membantu proses perancangan karakter menjadi lebih cepat dan terstruktur.

\section{Pembahasan}

Avatar dirancang dengan 2 gender yang berbeda dan setiap elemennya di-desain sesuai dengan class level yang tersedia. Tingkatan kelas avatar dibagi menjadi 4 bagian, yaitu: Basic Class, Intermediate Class, Advance Class, hingga Master Class. Kelas avatar disesuaikan dengan seberapa jauh pelajar dapat memahami dan berhasil mengerjakan materi yang disediakan. Perancangan digital avatar dilakukan karena ditemukan tingginya tingkat kemalasan pada pelajar di seluruh dunia yaitu sebesar 66\%. Besar persen tersebut menyatakan bahwa banyak pelajar mengalami kemalasan dan kesulitan dalam memahami materi yang diajarkan oleh pendidiknya (Doyle, 2020). Fenomena tersebut terjadi karena para pelajar tidak memiliki motivasi dalam belajar yang diajarkan secara tatap muka ataupun melalui online.

Perancangan ini diciptakan dengan tujuan memudahkan para pelajar untuk lebih memahami materi yang diajarkan oleh pengajar mereka. Perancangan ini melibatkan pelajar untuk secara aktif bermain sekaligus belajar. Dengan perancangan karakter digital avatar, visual pada karakter tersebut adalah elemen utama dalam proses perancangan. Desain visual pada karakter digital art juga dapat menghidupkan suasana cerita yang diciptakan dan membuatnya menjadi lebih atraktif saat dilihat (Yulianti, 2021). Tentu hal tersebut menjadi faktor utama yang paling penting dalam perancangan ini. Elemen design pada avatar harus dapat menarik perhatian pelajar untuk dimanfaatkan sebagai sistem pembelajarannya.

Sistem ini juga diterapkan dengan materi pembelajaran yang disediakan oleh pendidik dan pengerjaan kuis yang secara tidak biasa. Yaitu dengan cara avatars battlesystem sesama pelajar. Dalam perancangan ini, sistem pembelajaran yang digunakan adalah melalui perangkat lunak berbasis e-learning (LMS). Pelajar harus memilih terlebih dahulu apa character yang ingin dipakai saat memasuki babak pertama. Setelah avatar dipilih, pelajar bisa menentukan siapa orang atau temannya yang ingin diajak untuk saling bersaing. Avatar hanya bisa menyerang dengan menggunakan element / power sesuai yang dimiliki dari characternya. Pelajar yang memiliki score lebih unggul dapat mengganti avatarnya menjadi class yang lebih tinggi. Tidak menutup kemungkinan 
apabila pesaingnya juga dapat menyusul nilai lawannya jika bisa menjawab soal-soal selanjutnya dengan lebih cepat dan benar. Penerapan battle-system pada digital avatar dimaksudkan untuk menjadi bagian dari tingkat kecerdasan secara intelektual maupun emosional.

Dalam tahap perancangan / desain avatar, penulis akan melalukan pengembangan produk dengan metode PDDIE. Tahapan ini digunakan sebagai bentuk pengembangan produk berupa perancangan digital avatar dan juga media pembelajaran. Awal pengembangan digital avatar dibuat dengan melakukan gambaran kecil sebelum mengilustrasikannya. Designer akan dapat melihat dengan cepat dan efisien apa komposisi bagian yang harus ditambah dan bagaimana bentuk keseluruhan yang akan di-finalisasi. Hal tersebut yang kemudian dapat membuat keseluruhan proses perancangan menjadi lebih mudah dan lebih cepat. Karena designer tidak akan menggunakan banyak waktu untuk membuat sketsa secara detail / terperinci.

Selanjutnya pada tahap pengembangan, pembuatan prototype akan dilakukan. Prototype akan diawali dengan mengilustrasikan karakter-karakter avatar yang tersedia. Pada perancangan ini telah ditetapkan sebanyak 42 karakter avatar dengan 1 gender avatar (male). Kemudian masuk ke-sesi pewarnaan dan penggambaran skema elemen pada tiap avatar. Elemen di-desain berdasarkan karakter yang sesuai pada avatar, termasuk senjata-nya ataupun role-nya. Setelah perancangan selesai, proses exporting akan dilakukan untuk mendapatkan bentuk hasil akhirnya. Seluruh fase ini juga akan menggunakan bahan referensi untuk mencapai hasil akhir yang terbaik. Memiliki referensi yang tersedia di semua bagian proses ilustrasi dapat membuat desain avatar menjadi lebih cepat. Kemudian hasil akhir dari prototype itulah yang akan diserahkan terlebih dahulu kepada praktisi pendidikan / dosen pembimbing untuk diberikan evaluasi / penilaian terhadap produk akhir.

Pada proses pembuatan karakter avatar, awalnya penulis membuat sketsa ilustrasi terlebih dahulu untuk membuat struktur dan gesture pada badan avatar. Desain pada tahap ini akan menghasilkan sketsa line-art / kerangka dan kostum avatar yang kemudian diilustrasikan. Setelah sketsa berhasil dibuat, bentuk tubuh dan wajah avatar akan diilustrasikan dengan teknik Vector Drawing menggunakan Curvature Tool \& Pen Tool yang ada pada Corel draw. Penulis menggambar senjata avatar dengan menggunakan curvature tool dan menambah beberapa detail garis dan elemen pada senjata dengan 
menggunakan pen tool. Kemudian kostum warrior diilustrasikan menggunakan Freehand tool dan Artistic Effect Tool untuk membuat efek elemen terlihat lebih real. Kemudian pada proses coloring, penulis menggunakan Interactive Fill Tool untuk memberi warna pada semua bagian avatar. Avatar diberi nuansa warna sesuai yang telah ditentukan dengan efek fountain fill pada kostum avatar. Setelah proses coloring dilakukan, penulis akan merapikan avatar dengan menggunakan shape \& smooth tool. Desain pada tahap ini akan menghasilkan sebuah ilustrasi avatar yang siap untuk di-finalisasi. Di tahap menjelang akhir, avatar yang sudah diberi element effect dan telah difinalisasi melalui tahap coloring, akan di-export menggunakan format color RGB dan format output berupa PNG dengan ukuran proporsional (2480 x 5906 px). Referensi ilustrasi avatar diambil dari gambaran secara umum.

Di bawah ini merupakan hasil rancangan digital avatar sesuai dengan pembagian tingkatan / level avatar yang telah ditentukan:

\section{Basic class}

Pada kelas basic terdiri dari 4 jenis karakter avatar, antara lain:

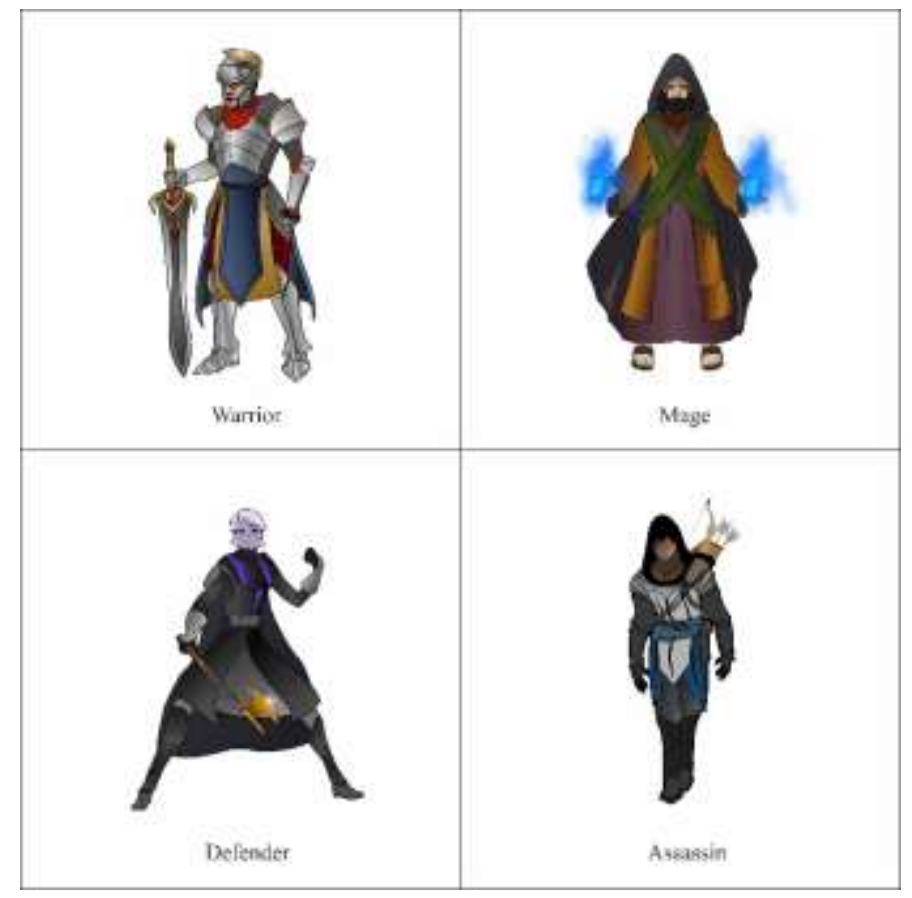

Gambar 2. Hasil digital avatar character 2D "Basic class" 


\section{Intermediate class}

Pada kelas intermediate terdiri dari 14 jenis karakter avatar, antara lain:

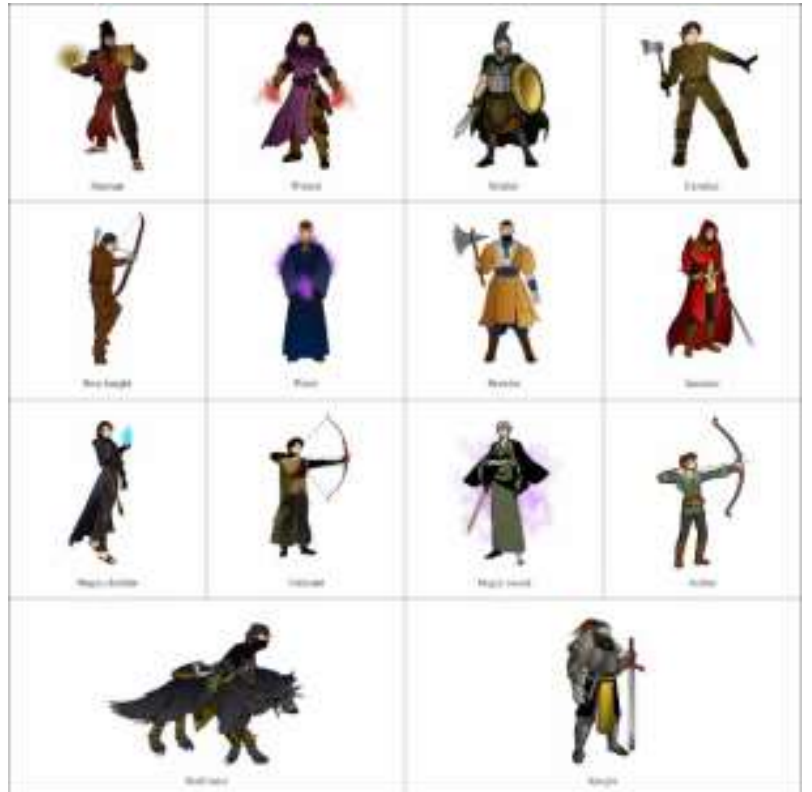

Gambar 3. Hasil digital avatar character 2D "Intermediate class"

\section{Advance class}

Pada kelas intermediate terdiri dari 14 jenis karakter avatar, antara lain:

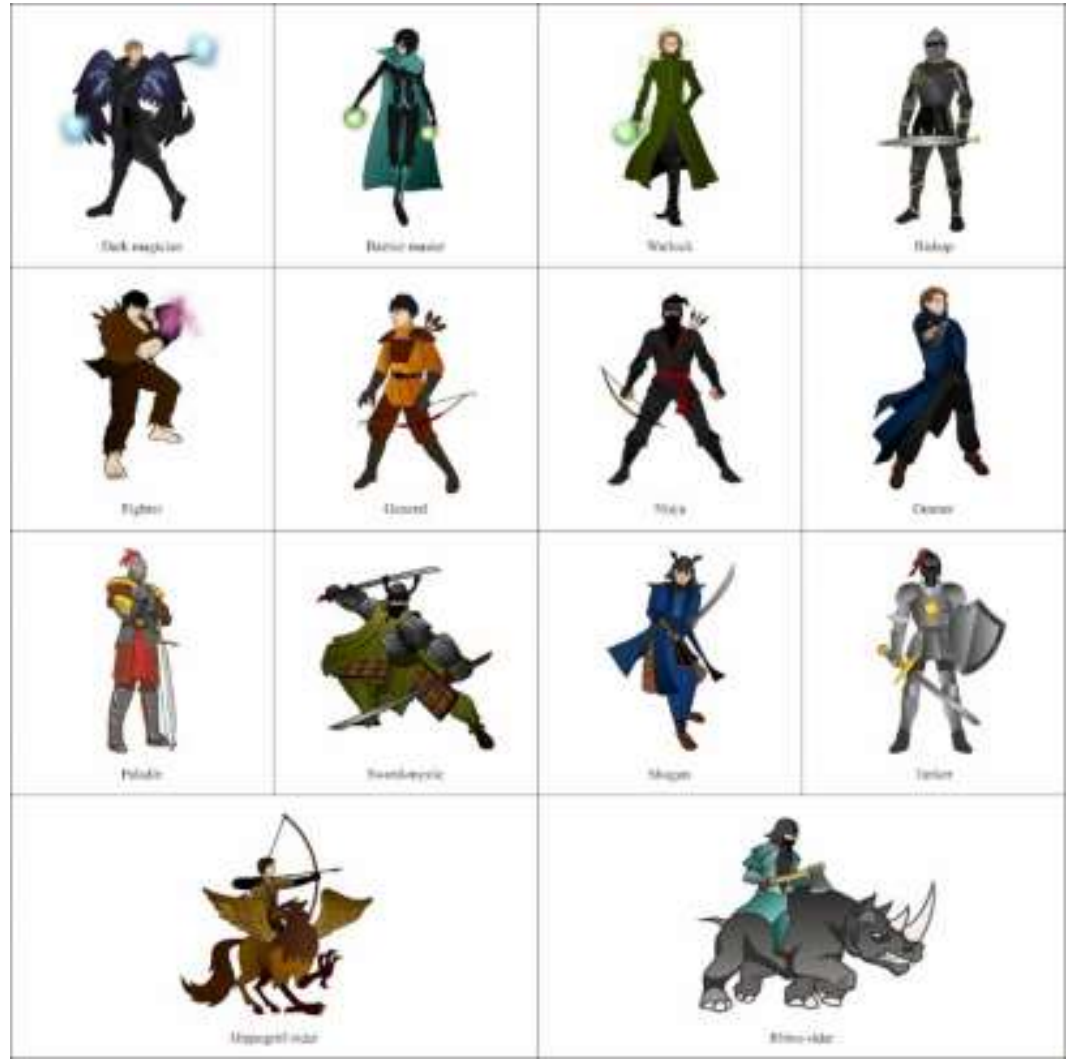

Gambar 4. Hasil digital avatar character 2D "Advance class" 
4. Master class

Pada kelas master terdiri dari 10 jenis karakter avatar, antara lain:

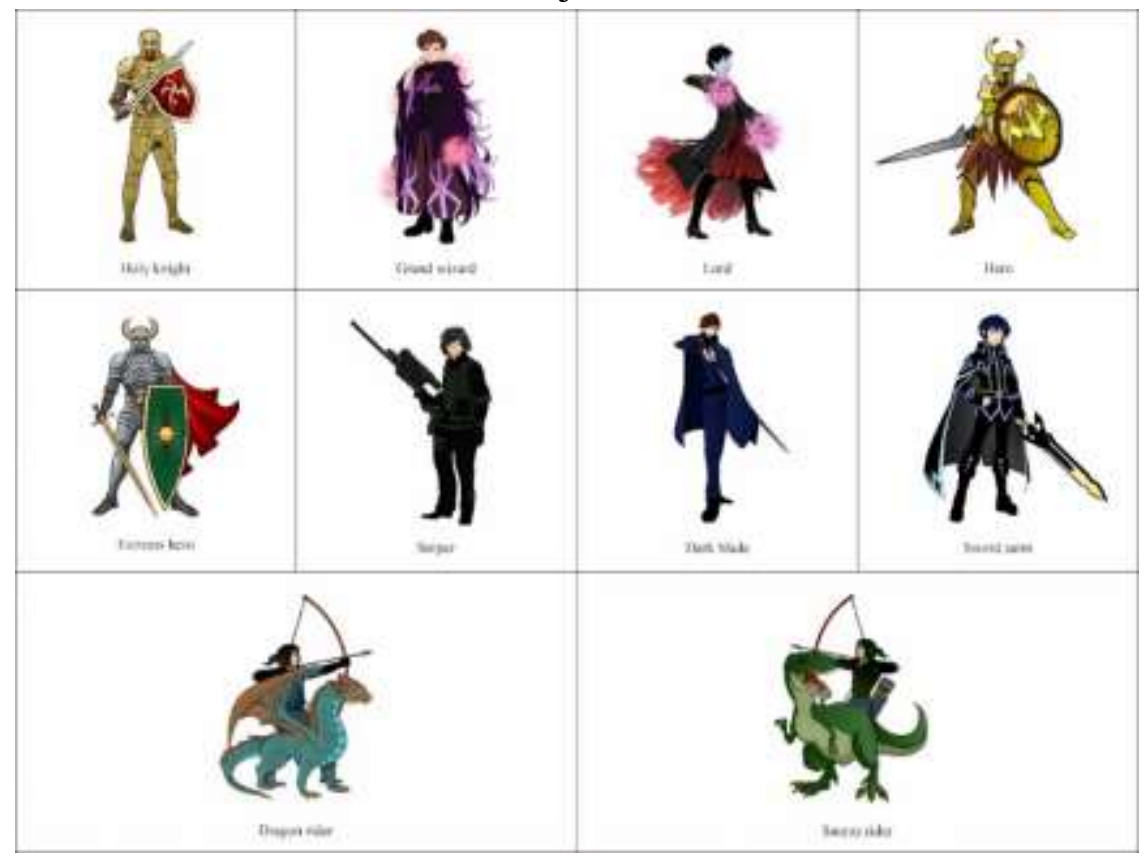

Gambar 5. Hasil digital avatar character 2D "Master class"

Dengan menggunakan bentuk penerapan berupa metode pengembangan PDDIE (Planning, Design, Develop, Implementing, Exporting) dan alur penelitian SICE (Sketching, Illustrating, Coloring, Export), penulis dapat menerapkan hasil rancangan digital avatar character $2 D$ ke dalam media pembelajaran dan menerapkan nilai-nilai pendidikan melalui sistem berbasis gamifikasi. Pelajar juga secara tidak langsung diajar untuk mengatur emosi saat bermain dengan para kompetitornya. Hal tersebut dapat memicu kesenangan dalam diri pelajar dan membantu mengubah pola sikap terhadap pembelajaran.

\section{Kesimpulan}

Penerapan digital art dalam pendidikan adalah untuk menjadikan proses pembelajaran menjadi hal yang menarik dan tidak membosankan bagi pelajar. Hasil yang didapatkan dari perancangan ini yaitu penulis dapat menciptakan aspek yang berbeda dalam proses pembelajaran dan membuat suasana pembelajaran menjadi lebih bermakna bagi pelajar ataupun pendidik. Selama perancangan karakter digital avatar $2 D$, peneliti mengambil peranan untuk mengerjakan tugas design pada digital art avatar yaitu dengan 
memperoleh list karakter terlebih dahulu dari development team. Penulis juga menanggapi kesulitan perancangan avatar sehingga selalu ada perubahan yang dilakukan agar hasil dapat segera diaplikasikan pada website LMS yang dirancang. Berbagai macam permasalahan yang ditemukan pada perancangan digital art avatar dari level basic hingga master dapat diselesaikan berkat kerangka kerja SICE yang dapat diaplikasikan terhadap pengembangan proyek yang dibuat. Kekurangan dalam penelitian ini perlu dijawab dengan eksplorasi lebih lanjut bagaimana digital avatar character $2 D$ dapat memberi efektivitas terhadap dunia Pendidikan masih perlu dijelaskan pada studi mendatang. 


\section{Referensi}

Antonaci, A., Klemke, R., \& Specht, M. (2019). The Effects of Gamification in Online Learning Environments: A Systematic Literature Review. Journal of Informatics, 6(3), 1-22.

Arifin, I., \& Wijaya, B. I. (2018). Ilustrasi Digital Komputer Bagi Pelajar SMA di Kota Makassar. Jurnal Pendidikan Seni Rupa, 1, 341-345.

Baca, M., Helmreich, A., \& Gill, M. (2019). Digital Art history. Journal of Visual Resources, 35(1-2), 1-5.

Basuki, Y., \& Hidayati, Y. (2019). Kahoot! or Quizizz: the Students' Perspectives. Journal of Psychology, 6(1), 2-10.

Doyle, P. M. (2020). ODU Digital Commons The Association of the National Assessment of Educational Progress Scores and Variance in State Education Requirements. Journal of Educational and Leadership, 1(1), 11.

Janottama, I. P. A., \& Putraka, A. N. A. (2017). Gaya dan Teknik Perancangan Ilustrasi Tokoh pada Cerita Rakyat Bali. Jurnal Segara Widya, 5(3), 25-31.

Jusuf, H. (2016). Penggunaan Gamifikasi dalam Proses Pembelajaran. Jurnal TICOM, $5(1), 1-6$.

Martin, F., \& Bolliger, D. U. (2018). Engagement matters: Student Perceptions on The Importance of Engagement Strategies in The Online Learning Environment. Online Learning Journal, 22(1), 205-222. https://doi.org/10.24059/olj.v22i1.1092

Richards, C., Thompson, C. W., \& Graham, T. C. N. (2017). Beyond Designing for Motivation: The Importance of Context in Gamification. Journal of Computer Human Interaction, 5(2), 217-226.

Tianean, J., Jimenez, B., \& Levey, S. (2020). Implementing Character Design Fundamentals through Digital Illustration. Journal of Culture and Arts, 1(1), 24.

Tjiptawan, J., Tedjokoesoemo, P. E. D., \& Rizqy, M. T. (2019). Perancangan Digital Art dan Lighting Surabaya Night Zoo di Kebun Binatang Surabaya. Intra, 7(2), 858868.

Verawati, N. (2020). Efektivitas Penggunaan E-Learning dalam Pengajaran di Kelas untuk Meningkatkan Kemampuan Berpikir Kritis Mahasiswa. Jurnal Ilmiah IKIP Mataram, 7(2), 168-175.

Wang, J. (2019). Application of Blending Learning based on Network Learning Space in Teaching Design of Digital Art. International Journal of Emerging Technologies in Learning, 14(3), 177-189.

Yulianti, I. (2021). Perancangan Desain Karakter Jole Berbasis Lokal Flores Indonesia. Journal of Animation \& Games Studies, 7(1), 63-72.

Zaini, M., \& Analisis, M. Z. (2017). Analisis Strategi Pemasaran Digital Art Melalui Ecommerce. Jurnal Ekonomi Syariah, 4(2), 14.

Zhou, S., \& Guo, J. (2018). Exploration of The Teaching of Digital Illustration Course. Advances in Social Science, Education and Humanities Research, 284(18), 2-3. 